\title{
Teaching and learning experience in soil consolidation aided by computer software
}

\author{
García-Ros, Gonzalo ${ }^{1}$; Sánchez Pérez, Juan Francisco²; García-Fernández, Martina ${ }^{3}$ \\ and Del Cerro Velázquez, Francisco ${ }^{3}$. \\ ${ }^{1}$ Civil Engineering Department, Technical University of Cartagena, Spain. ${ }^{2}$ Applied \\ Physics Department, Technical University of Cartagena, Spain. ${ }^{3}$ Electromagnetism and \\ Electronics Deparmtent, University of Murcia, Spain.
}

\begin{abstract}
The present article shows how the learning and personal motivation of the students in Geotechnics are improved through the realization of computer practices and thanks to the use of a software adapted to their needs. By means of a simple interface of data entry and output of results, students will master abstract concepts such as the excess pore pressure and the average degree of consolidation, while reinforcing their personal motivation, both to face the content of the subject and those of other disciplines of the Civil Engineering Degree.
\end{abstract}

Keywords: theoretical and personal objectives; geotechnics; soil consolidation; practical exercise; software. 


\section{Introduction}

After the good reception, on the part of the "Civil Engineering Master" students of the Technical University of Cartagena, of the computer practices sessions for the study of the consolidation of soils with vertical drains aided by computer software [SICOMED_3D (2017), García-Ros et al. (2017)], it was decided to imitate the experience for the students of the "Civil Engineering Degree" (certification that allows, later, to accede to the Civil Engineering Master) for the academic year 2017-2018.

For these students, in the second year of the Civil Engineering Degree, the subject "Geotechnics" is presented as a completely new discipline, of which they lack any previous experience, discovering for the first time a series of concepts (earth pressures, thrusts, deformations...) that require a high level of abstraction and that, in a large number of cases, pose an added difficulty when it comes to overcoming the subject and understanding the important basic concepts for their training that are treated along the course.

In this way, and thanks to the vast experience of the "Network Simulation" research group of the Technical University of Cartagena in the development of software for educational purposes (and also professional), it was decided to create EDUCONSOL (2018), an agile program with a very simple graphical interface with which one-dimensional soil consolidation problems can be solved.

\section{Objectives of the teaching and learning experience}

The learning experience through computer practices carried out has as its main mission to complement the training of the student acquired in the theory classes, where the basic concepts that govern the consolidation problem are exposed [Berry and Reid (1987), Braja (2008), Wood (2009)]: excess pore pressure dissipation (of the water contained in the soil) and settlement evolution. These concepts are also practiced in the theory classes by solving exercises of varying difficulty.

Within the purely technical objectives, this computer practices aim to help the student in understanding the basic concepts that govern and characterize the consolidation problem: excess pore pressure, average degree of consolidation and settlements produced. But, in addition, the experience also aims to encourage the motivation of the student for the subject, contribute to overcoming the subject (in a more comfortable and rewarding way), encourage cooperation between students and teamwork and increase, in general, the motivation of the student for the degree they are studying. Table 1 summarizes the objectives that are to be achieved with the teaching and learning experience proposed. 
García-Ros, G.; Sánchez Pérez, J.F.; García-Fernández, M.; Del Cerro Velázquez, F.

Table 1. Objectives of the teaching and learning experience with EDUCONSOL

Technical knowledge

Excess pore pressure

Average degree of consolidation

Settlements produced

\section{Student experience}

Motivation for the subject

Contribution to pass the subject

Cooperation between students and teamwork

Motivation of the student for the degree

\section{Practical exercise development}

The practical experience consists of a 2-hour session in which students are proposed a soil consolidation exercise similar to those that have already been solved in class. At the beginning of the session, students are explained the objectives that are pursued with the practice, the problem is stated and the EDUCONSOL software is presented, helping them to start the program and explaining its operation: introduction of data to the program and obtaining results, Figures 1 and 2.

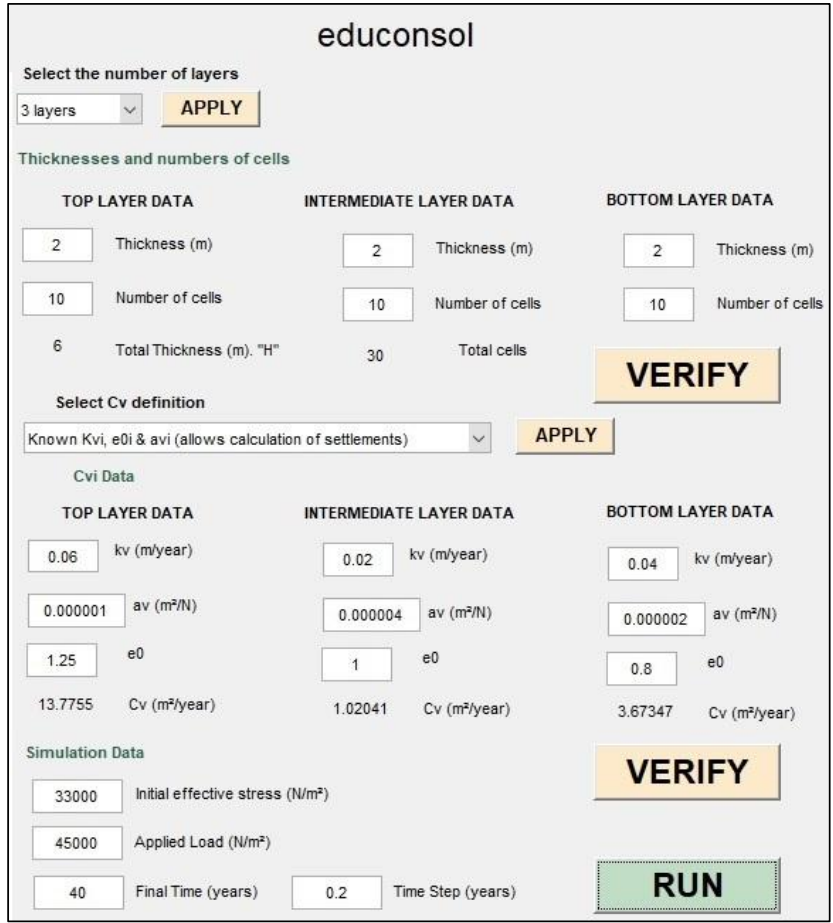

Figure 1. EDUCONSOL data entry screen. 


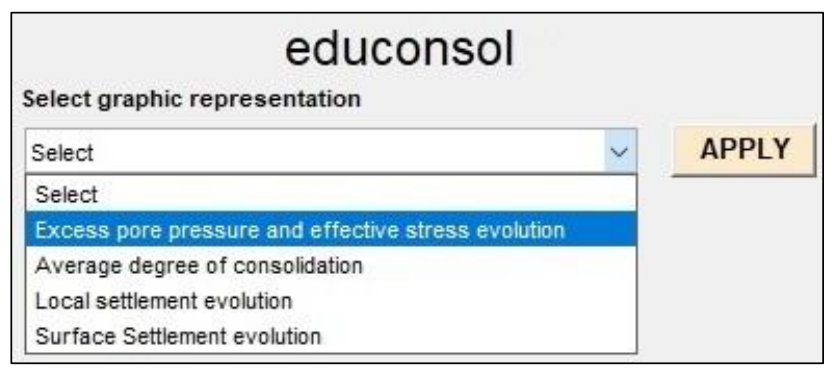

Figure 2.EDUCONSOL selection of representations screen.

After this exposition, students are invited to face the resolution of the problem without the help of the teacher, encouraging them to discuss among themselves, if necessary, the main questions that may arise. During this stage, the teacher will closely supervise the work of the students and will solve the doubts and the problems of use of the software when it is considered appropriate, so that, after approximately one hour since the beginning of the session, all the students have been able to solve the problem satisfactorily. Once this is achieved, and thanks to the simple program output interface, students will be able to discuss and interpret all the results obtained, Figures 3-6.

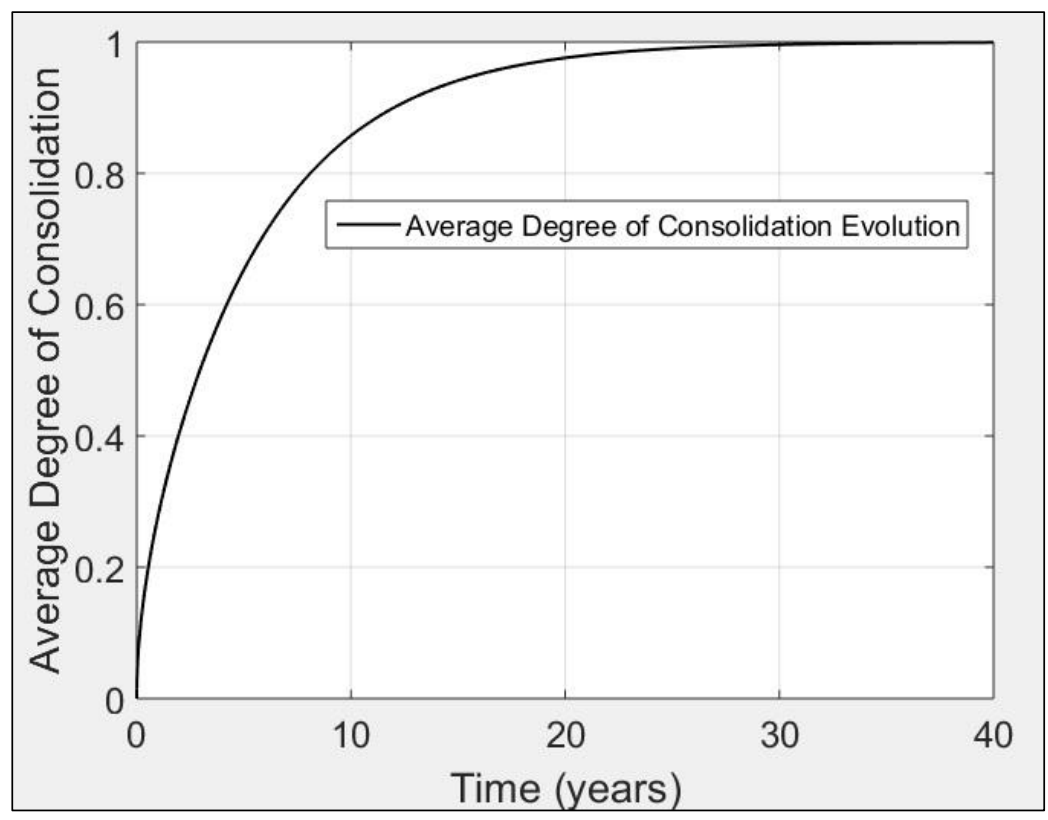

Figure 3. Average degree of consolidation evolution. 
García-Ros, G.; Sánchez Pérez, J.F.; García-Fernández, M.; Del Cerro Velázquez, F.

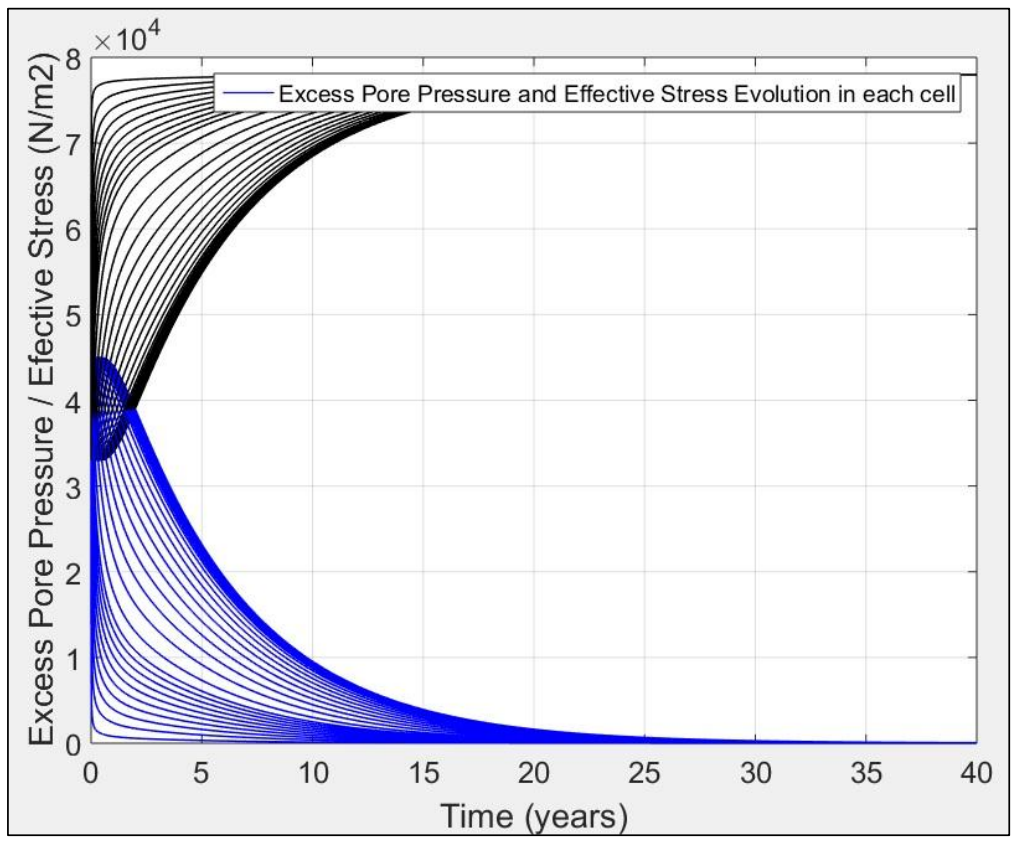

Figure 4. Excess pore pressure evolution and effective stress.

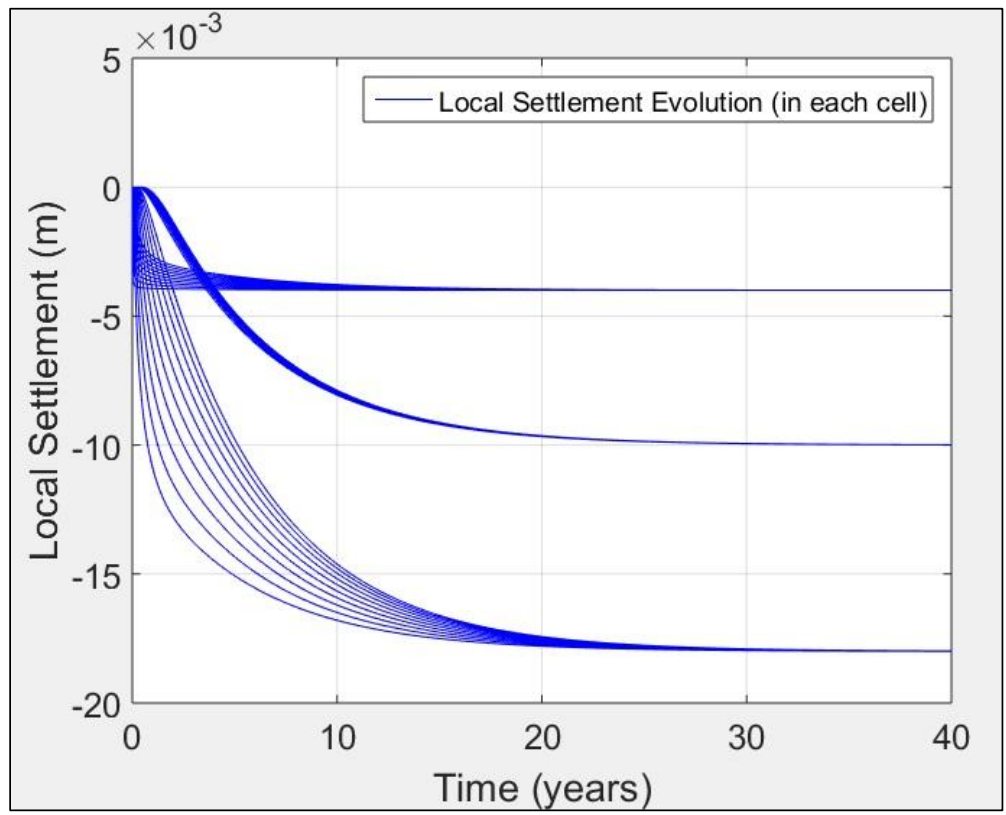

Figure 5. Local settlements evolution. 


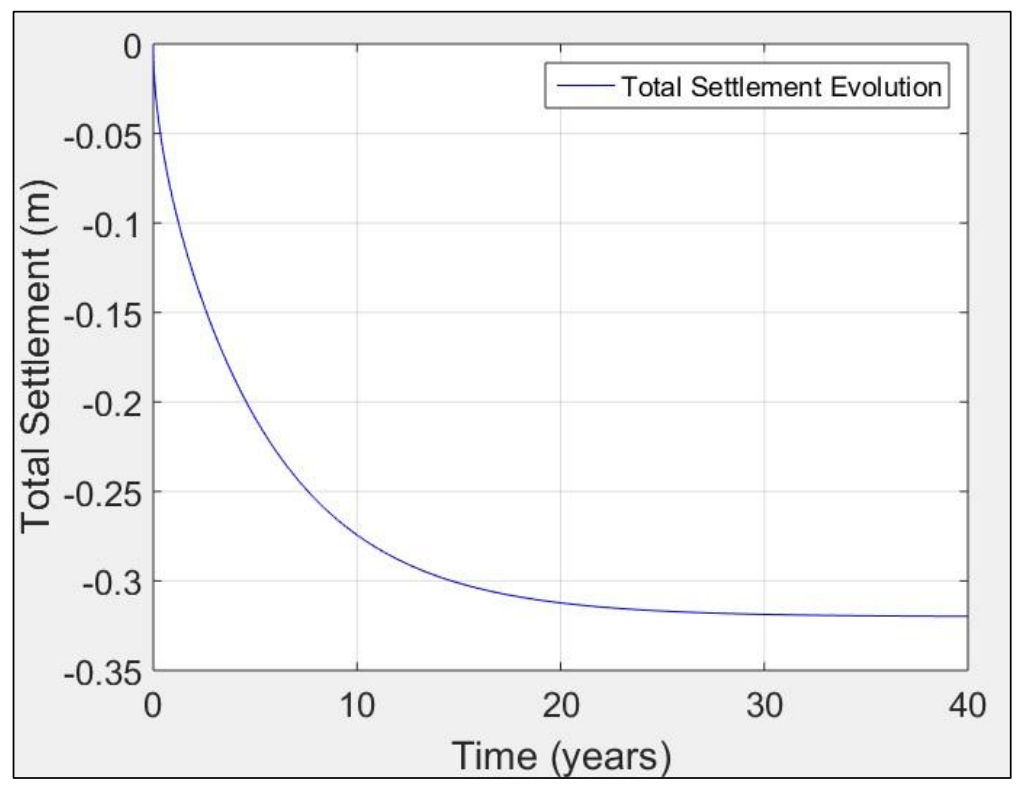

Figure 6. Surface settlement evolution.

\section{Results and achievements of the experience}

Once the discussion of results was concluded (emphasizing the theoretical-technical concepts used), a survey was performed to the students in order to obtain an evaluation on the fulfillment of the technical and motivational objectives. The survey was conducted on a sample of 28 students; 23 of them were freshmen, while 5 were repeating. In order not to condition the answers of the students, the surveys were done anonymously. The results are summarized in Tables 2 and 3.

Table 2. Assessment of the students on the influence of the practical experience in the acquisition of technical knowledge.

\section{Improvement in the acquisition of technical concepts Positive evaluation of the student}

Excess pore pressure

Average degree of consolidation

Settlements produced
$92.9 \%$

$71.4 \%$

$85.7 \%$ 
It is very interesting to check that, in terms of the technichal concepts addressed (Table 2), the students state that practical experience with EDUCONSOL has allowed them to make significant progress in understanding the concept of excess porel pressure, which they had not fully understood (most of them) after the theoretical classes. Indeed, thanks to graphical representations like the one shown in Figure 3, students can observe how the pore pressure drops during the consolidation process. For the concepts of average degree of consolidation and settlements, the students said they had also experienced an important improvement.

Table 3. Assessment of the students on the influence of the practical experience on their personal motivation.

Improvement in personal motivation Positive evaluation of the student

$\begin{array}{cc}\text { Motivation for the subject } & 82.1 \% \\ \text { Cooperation between students and teamwork } & 60.7 \% \\ \text { Contribution to pass the subject } & 89.3 \%\end{array}$

Regarding the influence of the experience in the personal motivation of the students, Table 3 , it is worth noting the important positive influence that its realization has on the perception of the students about the subject: on the one hand, the understanding of the complexes theoretical concepts increase the motivation of the students for the subject, while they affirm that the practical realization of the exercise will have a positive impact on their options to pass the subject. As a pending objective for the upcoming courses, it is necessary to reconsider the proposed exercise in a way that encourages, even more, teamwork and cooperation among the students. In this regard, a possible alternative to encourage debate and cooperation is to include a section in the practical session in which they must modify the statement of the problem so that it resembles a real case that they know (or that has been previously exposed in the theoretical classes.

Due to the satisfactory results obtained, the teaching and learning methodology presented in this paper is going to be applied in future practical sessions. Thus, in the next academic year the students of "Geotechnics" will also carry out computer practices sessions of seepage under dams, a matter also unknown and complicated for them, which they must face for the first time. The software is currently in the last phase of development and will be ready for the next course. Later, practical sessions will be included for the calculation of elastic settlements by means of a software whose development has just begun and will be ready in 1 or 2 years. 
At the same time, the methodology will be implemented in the subject "Geotechnics and Foundations" of the "Civil Engineering Master", where problems of consolidation with preloads, stability of slopes and thrusts on retaining walls will be analyzed. During the process of implementation, both in the master and the continuation in the "Civil Engineering Degree", an exhaustive monitoring will be carried out focused on improving the methodology and adjusting it to the students needs. The comparison of results will allow to identify differences (associated, for example, with the level of studies, degree or master), in order to adjust the contents so that the degree computer practices serve as a basis for future master practices (and vice versa, that the master practices serve as a complement and reinforcement of what was learned in the degree).

\section{References}

Berry, P.L. and Reid, D. (1987). An Introduction to Soil Mechanics. McGraw-Hill, London.

Braja, D. (2008). Advanced soil mechanics. Taylor and Francis, New York and London.

EDUCONSOL [software] (2018). ('Educational Consolidation'). García-Ros, G. and Alhama, I. Intellectual Property Registration, Murcia, Spain.

García-Ros, G., Alhama, I., Cánovas, M. and Pérez, J. F. (2017). An educational software for teaching soil consolidation. 3rd International Conference on Higher Education Advances, HEAd'17, 865-872

SICOMED_3D [software] (2017). ('Simulación de consolidación con mechas drenantes'). (C) Universidad Politécnica de Cartagena, García-Ros, G., Alhama, I. and Sánchez Pérez, J.F.

Wood, D. M. (2009). Soil mechanics: a one-dimensional introduction. Cambridge University Press, New Delhi. 